\title{
Mechanical Properties of Paste Slurry under Constant Shear Rate in Initial Structure Failure Process
}

\author{
Chaoqun Dai $\mathbb{D}^{1,2}$ Aixiang Wu ${ }^{10},{ }^{1,2}$ Yan Qi, ${ }^{1}$ Zhiqiang Chen, ${ }^{1}$ and Bin $\mathrm{Li}^{1}$ \\ ${ }^{1}$ School of Civil and Resource Engineering, University of Science and Technology Beijing, Beijing 100083, China \\ ${ }^{2}$ Key Laboratory of the Ministry of Education of China for High-Efficient Mining and Safety of Metal Mines, \\ Beijing 100083, China \\ Correspondence should be addressed to Chaoqun Dai; s20170079@xs.ustb.edu.cn
}

Received 28 January 2019; Revised 19 March 2019; Accepted 18 April 2019; Published 8 September 2019

Academic Editor: Luigi Nicolais

Copyright (c) 2019 Chaoqun Dai et al. This is an open access article distributed under the Creative Commons Attribution License, which permits unrestricted use, distribution, and reproduction in any medium, provided the original work is properly cited.

\begin{abstract}
At constant shear rate, the process of deformation of the paste slurry is divided into two stages: one is the initial structural failure process with increasing shear stress; the other is the thixotropic process with decreasing shear stress after yielding. Based on experiments, the mechanical response characteristics of the paste slurry in the initial structural failure process under different shear rate conditions were studied in this paper. At the same time, according to the Maxwell model, the stress-time model equation describing the initial structure failure stage of the paste was deduced and the constant shearing test was carried out on the paste slurry at different mass concentrations; the model equation was used to fit the test data of the initial stress increment stage. The results showed that the model equation had higher prediction accuracy and better popularity. In the initial structural failure stage, the paste had a nonlinear stress-time relationship. At different shear rates $\left(0.05,0.5\right.$, and $\left.1 \mathrm{~s}^{-1}\right)$, the lower the rotation speed, the smoother the curve, and the slurry at various stages in the yielding process could be more clearly reflected; in the range of low constant shear rate $\left(0.03,0.05\right.$, and $\left.0.07 \mathrm{~s}^{-1}\right)$, the initial stress and yield stress of the paste increased with the increase of shear rate at the same mass concentration, and the time to yield was shorter. The yield stress increased exponentially with mass concentration.
\end{abstract}

\section{Introduction}

The filling mining method backfills the surface-stacked waste into underground treatment empty areas and has become the safest, most efficient, and environmentally friendly mining method for the mine. Paste filling has the characteristics of nonsegregation, nonprecipitation, nondehydration, large filling capacity, and low filling cost and is an important direction for China's mining development and has broad application prospects $[1,2]$.

During the filling process, pipeline accidents caused stoppages or planned stops occasionally. When the paste slurry is at rest, the hydration hardening effect of the cement is gradually enhanced and the internal floc structure is gradually developed. The hydration product closely connects the inert tailings particles to form a spatial network structure with a certain strength; the system resists external disturbance is gradually enhanced, causing the paste slurry to lose fluidity as a whole, exhibiting a solid-like character [3]. The pressure required to restart the pipeline transportation is bound to be higher than the normal pipeline delivery pressure and even a pipe burst accident. Therefore, studying the mechanical response characteristics of structural failure during the initial startup of paste slurry can provide theoretical guidance for pipeline design and is very beneficial for ensuring pipeline safety and economic operation.

The predecessors have conducted a lot of research on the pipeline transportation process during the filling process. Pullum [4] according to the mode of transport of the slurry in the pipeline divided them into three modes: homogeneous flows, hybrid flows, and granular flows. Yao [5] combined with the flow characteristics of the paste in the pipe and proposed the concept of structural flow. In the aspect of the resistance prediction model, based on diffusion theory, gravity theory, and energy theory [6], the researchers proposed Jinchuan formula, Durand formula [7], and 
Buckingham formula derived from non-Newtonian fluid mechanics [8]. In recent years, some scholars have obtained the corresponding resistance calculation model according to the characteristics of the paste structural flow and the analysis of the flow force state in the pipe based on the Bingham rheological model [9]. Haimoni [10] combined rheology with experimental tests and proposed a method for predicting pipe flow resistance considering time variation and wall-slip characteristics.

However, most of these models were based on the thixotropic rheological equation which focused on the structural breakdown process after the yield of the paste slurry and derived the corresponding resistance calculation formula; there was little research on the initial structural failure process of yielding. This paper was based on the experiments and qualitative and quantitative analyses of the mechanical response characteristics in the initial structural failure process of the paste.

\section{Paddle Rheometer Principle and Measurement Method}

The paddle rheometer test principle is shown in Figure 1. Since the yield occurred near the cylindrical surface generated by the rotation of the vane rotor and the yielding was the slurry itself, the wall-slip effect was avoided $[11,12]$. The vane needed to overcome the yield stress of the slurry to rotate, the rotation caused the slurry in a certain area to shear, and the yield area along the cylindrical surface was $\pi d h+2\left(\pi d^{2} / 4\right)$. It was assumed that the shear stress was evenly distributed anywhere on the cylinder and equal to the yield stress $\left(\tau_{y}\right)$ when the torque was maximum $\left(T_{m}\right)$. At this time, the relationship between shear stress and torque was as follows [13]:

$$
T=\frac{\pi d^{3}}{2}\left(\frac{h}{d}+\frac{1}{3}\right) \tau,
$$

where $T$ is the torque applied to the vane, $N \cdot m ; \tau$ is the shear stress, pa; $d$ is the diameter of the vane, $\mathrm{m}$; and $h$ is the vane height, $\mathrm{m}$.

In order to eliminate the boundary effect during the test, the rotor needs to meet the position requirement when inserting the test sample [14]:

$$
\begin{aligned}
& L / d>1, \\
& Z / d>0.5, \\
& D / d>2,
\end{aligned}
$$

where $D$ is the beaker diameter, $\mathrm{m}$; $L$ is the distance from the top of the rotor to the upper surface of the slurry; and $Z$ is the distance from the underside of the rotor to the bottom of the beaker.

\section{Mechanical Properties and Model Establishment}

The vane method provides means for direct measurement of the true yield stress of concentrated suspensions under

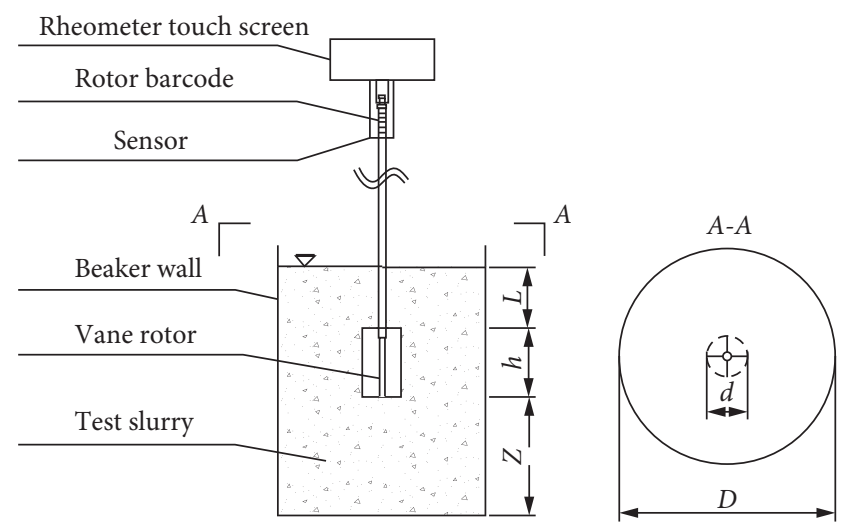

FIgure 1: Paddle rheometer test principle.

virtually static conditions. It applies the fundamental concept of the yield stress as a true material property associated with the strength of a continuous network structure found in flocculated suspensions [15].

When an external shear rate $\gamma$ was imposed on a soft solid at time $t=0$ and was kept constant thereafter, the stress $\sigma_{t}$ first increased with the strain $\gamma=\dot{\gamma} \cdot t$. Such behavior may be attributed to the mere stretching of the "network bonds" interconnecting the structural elements (particles or aggregates or both). Since more bonds would be stretched and the resistance to more deformation increased as the vane's rotation continued, the torque required to keep the motion constant must also rise [16]. Breaking of the already stretched bonds would eventually occur even though in a gradual manner.

Finally, when all (or a majority) of the network bonds had been broken, the network would collapse, and microscopically, the material may be said to yield. Furthermore, since hydrodynamic forces at extremely low shear were not strong enough to bring the separated structural elements close together for a reformation of the network bonds, the material would yield in an irreversible manner with "cracks" (visible or invisible) formed in a localized yield area. This explained the existence of a maximum shear stress value followed by a rapid fall off in stress with time on the stresstime response [17-19].

Fully immersed the vane rotor in the slurry and rotated at a constant speed, the shear stress was measured as a function of shear strain or time as shown in Figure 2. The curve was divided into two parts: AB segment was the stress rise phase which was the initial structural failure process [20-22] and BC segment was the stress decay phase which was the thixotropic process $[23,24]$.

$A B$ segment was the process of the initial structural failure of the slurry and was the focus of this study. The peak of the curve was the dynamic yield stress $\left(\tau_{y(d)}\right)$ which was taken as the true yield stress of the material [25-27] since it represented the full breakdown of the structural network $[28,29]$. Taking into account the experiment was carried out at a constant shear rate, in the presence of $\gamma=\dot{\gamma} \cdot t$ [30], the stress-strain relationship of Maxwell was used to derive the corresponding stress-time equation. The variable $\eta$ in the Maxwell model represented the generalized dynamic 


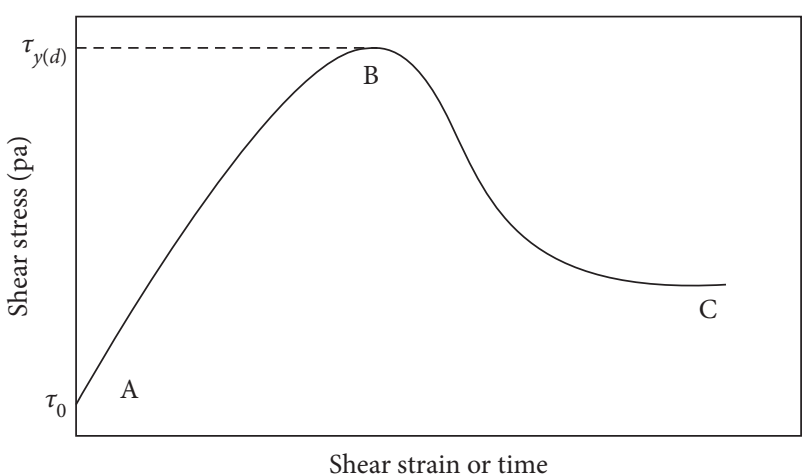

FIGURE 2: Sketch of the stress response in a startup experiment at a constant shear rate.

viscosity, which was the embodiment of the "viscosity" and "structure" of the paste. Therefore, it was different from the apparent viscosity of the paste in the traditional Bingham curve test.

The expression of the Maxwell model was as follows [31]:

$$
\frac{\tau}{\eta}+\frac{\dot{\tau}}{G}=\dot{\gamma}
$$

Since the shear rate $\dot{\gamma}$ in the test was constant (ignoring the acceleration process of the rotor in the initial very short time), the rate of stress change could be written as follows:

$$
\dot{\tau}=\frac{d \tau}{d t} .
$$

On combining and then simplifying (3) and (4), the following equation is obtained:

$$
\frac{d \tau}{d t}+\frac{G \tau}{\eta}=G \dot{\gamma}
$$

Solving the first-order linear nonhomogeneous equation, we get

$$
\tau(t)=C e^{-(G / \eta) t}+\eta \dot{\gamma}
$$

Due to inertia and transient elastic response, the initial moment stress at the start was not zero:

$$
t=0, \tau(0)=\tau_{0} .
$$

Therefore, applying appropriate modifications in formula (7), we get

$$
\tau(t)=\left(\tau_{0}-\dot{\gamma} \eta\right) e^{-(G / \eta) t}+\eta \dot{\gamma}
$$

where $\tau_{0}$ is the initial shear stress at the moment of startup and $G$ is the elastic modulus.

Equation (8) was an equation according to the Maxwell model to describe the stress-time relationship of the paste slurry in the initial structural failure process.

\section{Experiment}

4.1. Experimental Materials. The experimental materials were taken from a gold mine unclassified tailings in China.

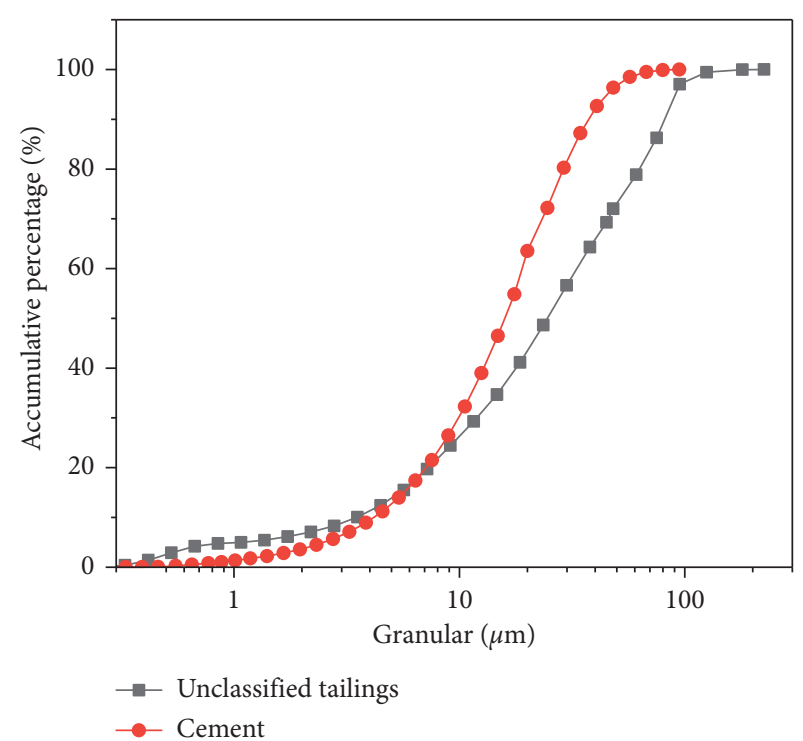

FIGURE 3: Granular distribution of unclassified tailings and cement.

The granular distribution curve is shown in Figure $3 . d_{10}, d_{30}$, and $d_{60}$ were the mesh diameters through which the cumulative content of $10 \%, 30 \%$, and $60 \%$ particles could pass. From Figure $3, d_{10}=3.53 \mu \mathrm{m}, d_{30}=11.60 \mu \mathrm{m}$, and $d_{60}=$ $32.12 \mu \mathrm{m}$. The total fines content of $-20 \mu \mathrm{m}$ in the tailings was $42.2 \%$, which was considered as ultrafine unclassified tailings [32], the density of tailings is $2.765 \mathrm{t} / \mathrm{m}^{3}$, the bulk density is $1.238 \mathrm{t} / \mathrm{m}^{3}$, the dense bulk density is $1.458 \mathrm{t} / \mathrm{m}^{3}$, the loose porosity is $55.31 \%$, and the dense porosity is $47.29 \%$. P.O 32.5 cement and laboratory tap water are added, the cement has the density of $3.03 \mathrm{t} / \mathrm{m}^{3}$, the specific surface area of $380 \mathrm{~m}^{2} / \mathrm{kg}$, and the dense bulk density of $1.424 \mathrm{t} / \mathrm{m}^{3}$. The granular distribution of the cement is shown in Figure 3.

4.2. Experimental Equipment. The experimental test equipment adopted Brookfield's R/S type rheometer, which has the advantages of effectively reducing the wall-slip effect without destroying the internal floc structure of the paste $[28,33]$; it was equipped with a V40-20 vane rotor; the monitoring data were imported into the computer and analyzed by software, as shown in Figure 4.

4.3. Mechanical Response Test of Paste Slurry. In order to understand the effect of shear rate on the failure process of the paste slurry structure, $71 \%, 73 \%, 75 \%$, and $77 \%$ mass concentration paste were tested at a constant shear rate, respectively. After inserting the rotor into the specified position, the rheological parameters of the material were measured at different shear rates $\left(0.05,0.5\right.$, and $\left.1 \mathrm{~s}^{-1}\right)$ to obtain the shear stress-time curve, as shown in Figure 5. By analysis of stress-time curves at different shear rates for each group, the dynamic yield stress at shear rate of $0.05 \mathrm{~s}^{-1}$ and the peak stress at shear rate of $0.5 \mathrm{~s}^{-1}$ and $1 \mathrm{~s}^{-1}$ were obtained, as shown in Table 1.

From Figure 5, the curve with lower shear rate $\left(0.05 \mathrm{~s}^{-1}\right)$ was more in line with the shape of the classical stress-time 


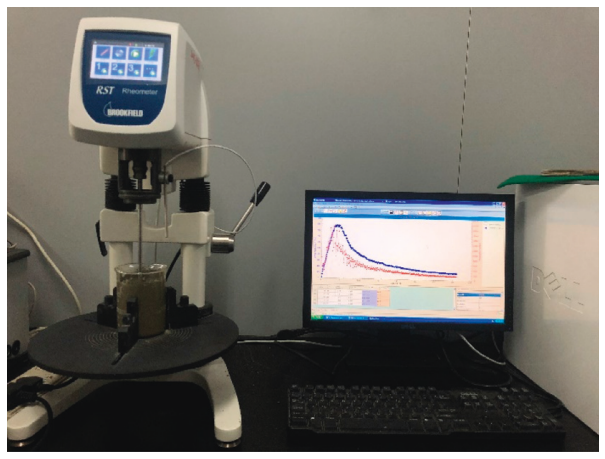

Figure 4: Brookfield R/S rheometer.
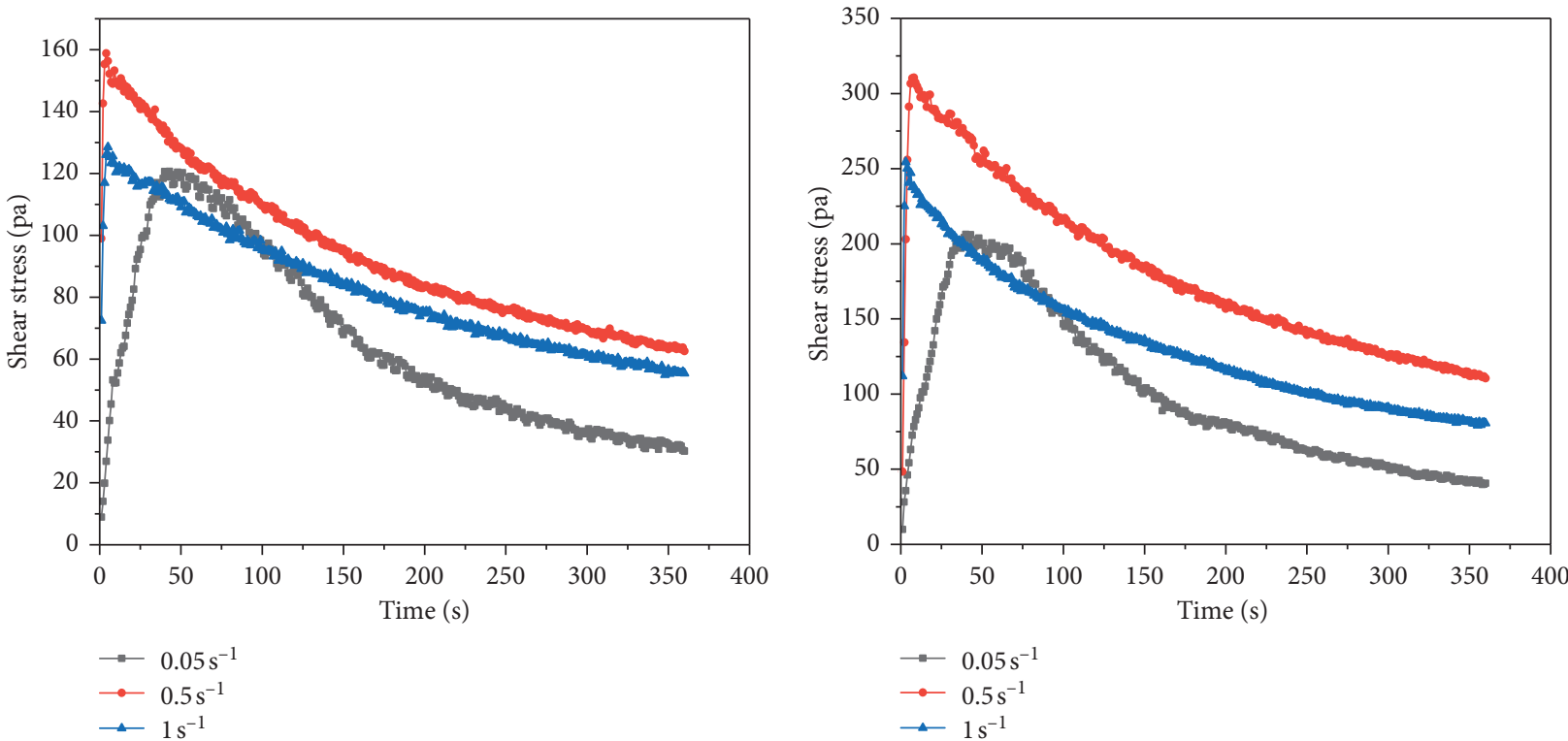

(a)

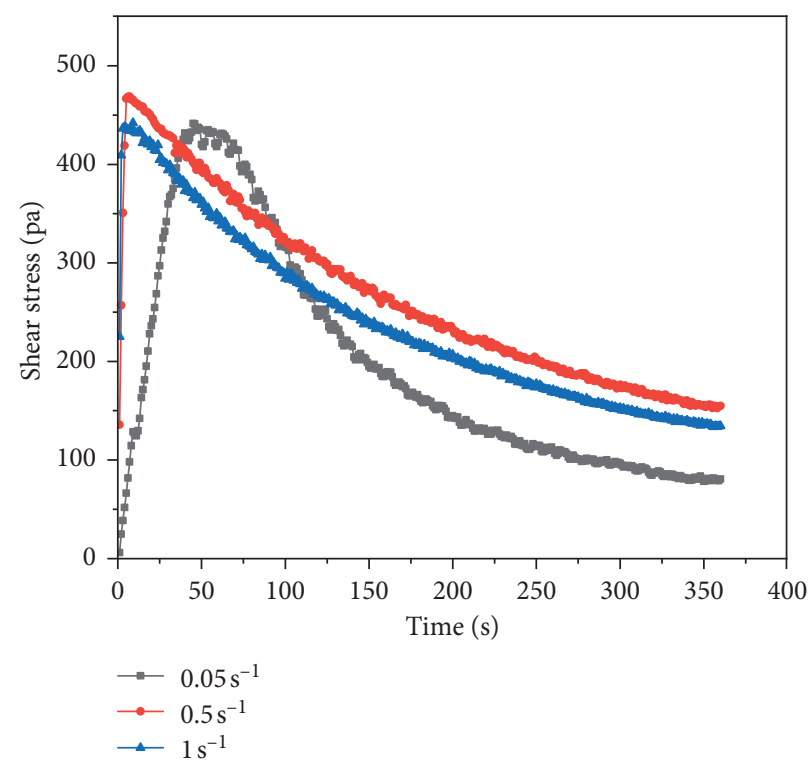

(c)

(d)

FIGURE 5: Shear stress-time curve at different shear rates. Mass concentration (\%): (a) 71; (b) 73; (c) 75 ; (d) 77. 
TABLE 1: Dynamic yield stress and peak stress of slurry with different mass concentrations.

\begin{tabular}{lcrr}
\hline \multirow{2}{*}{ Mass concentration (\%) } & Dynamic yield stress (pa) & \multicolumn{2}{c}{ Peak stress (pa) } \\
\hline 71 & $0.05 \mathrm{~s}^{-1}$ & $0.5 \mathrm{~s}^{-1}$ & 158.85 \\
73 & 120.27 & 310.59 & 128.54 \\
75 & 206.28 & 468.80 & 254.39 \\
77 & 441.53 & 819.52 & 438.02 \\
\hline
\end{tabular}

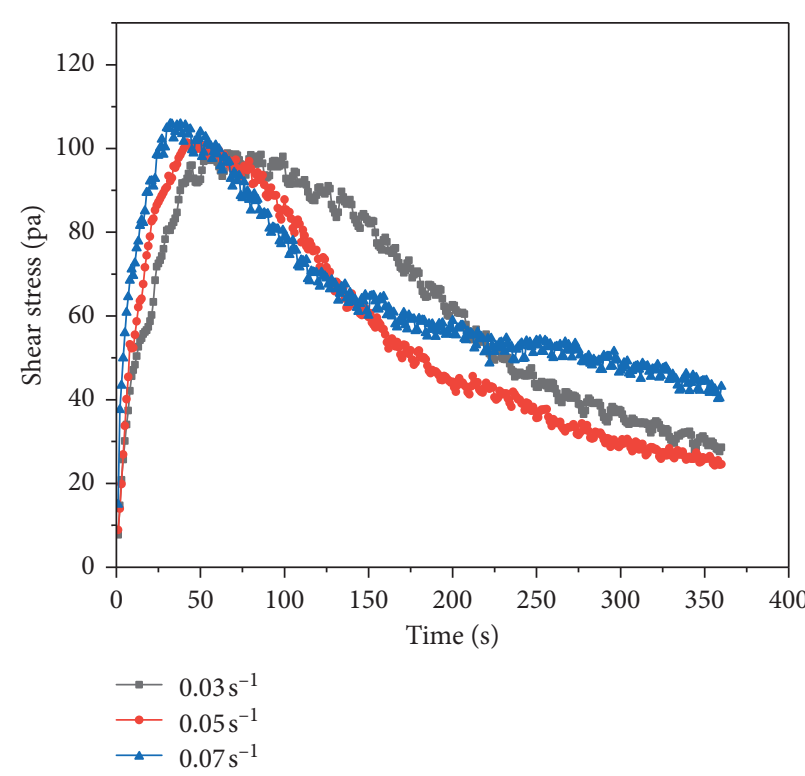

(a)

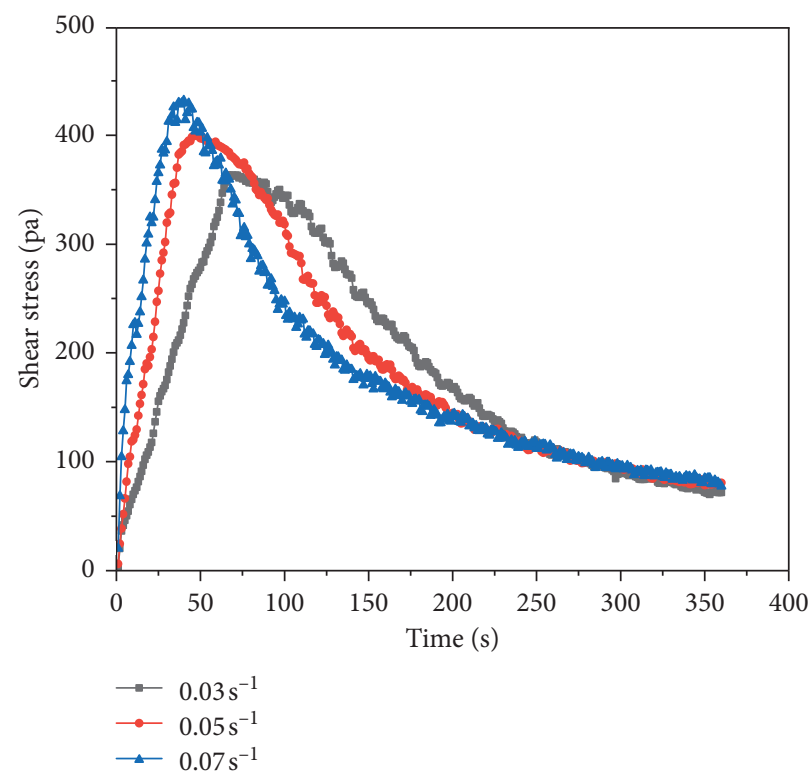

(c)

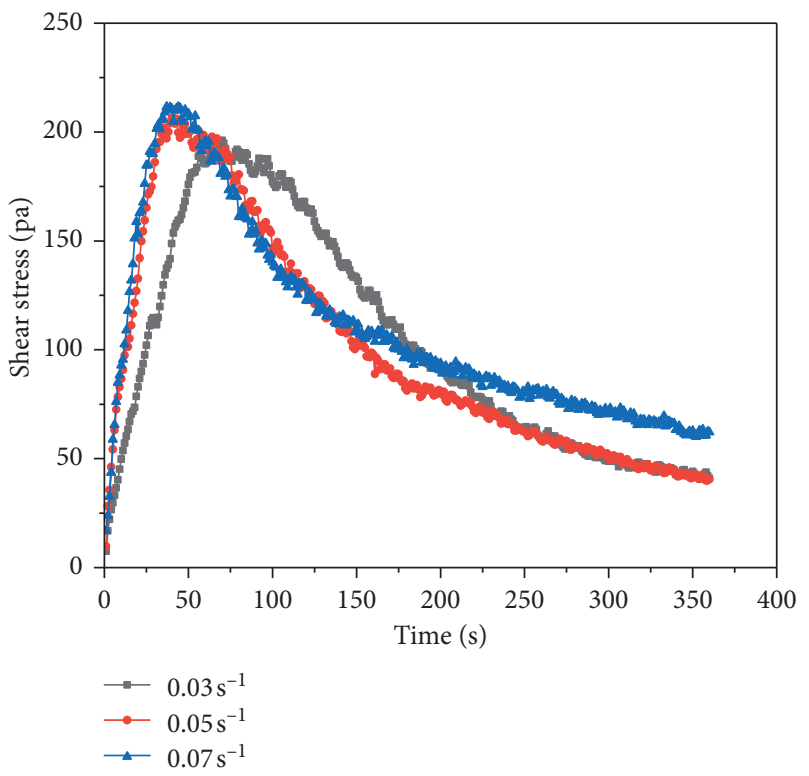

(b)

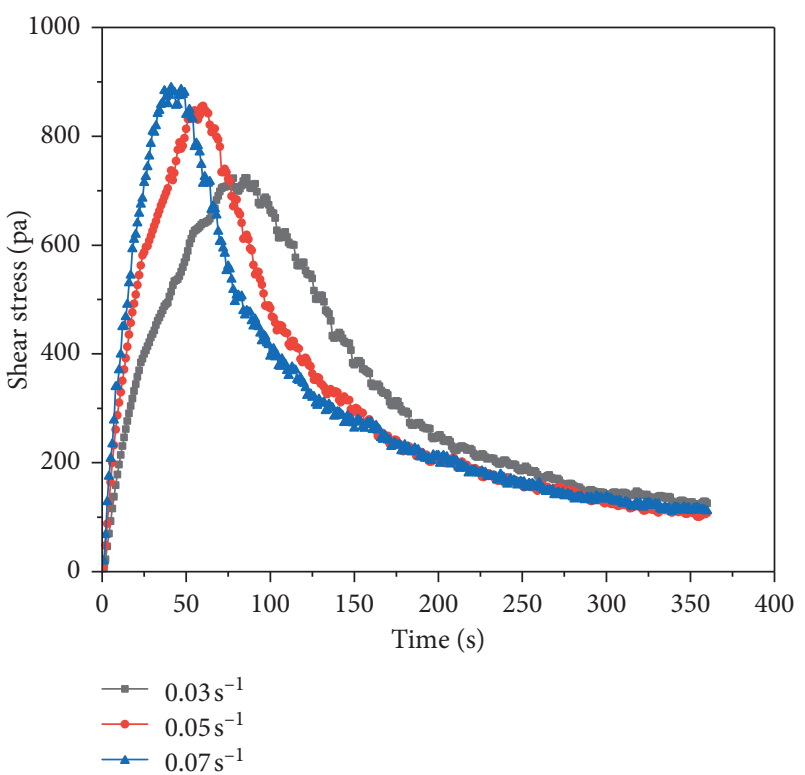

(d)

FIgURE 6: Shear stress-time curve at different low shear rates. Mass concentration (\%): (a) 71; (b) 73; (c) 75 ; (d) 77.

curve, the curve was more gradual, and the various stages of the yielding process were clearly reflected. High mass concentration slurry and low mass concentration slurry exhibited different characteristics when the shear rate employed was higher. From Figures 5(a) and 5(b), the peak stress of $0.5 \mathrm{~s}^{-1}$ and $1 \mathrm{~s}^{-1}$ was much higher than the result of $0.05 \mathrm{~s}^{-1}$. Because when the rotor moved at a relatively fast speed, it was not only affected by the yield stress but also 


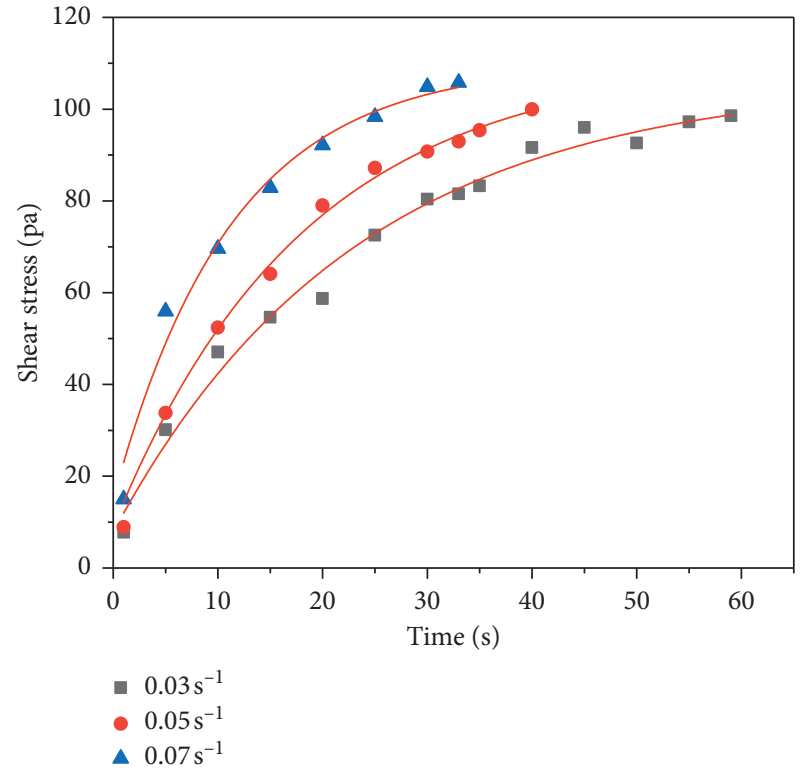

(a)

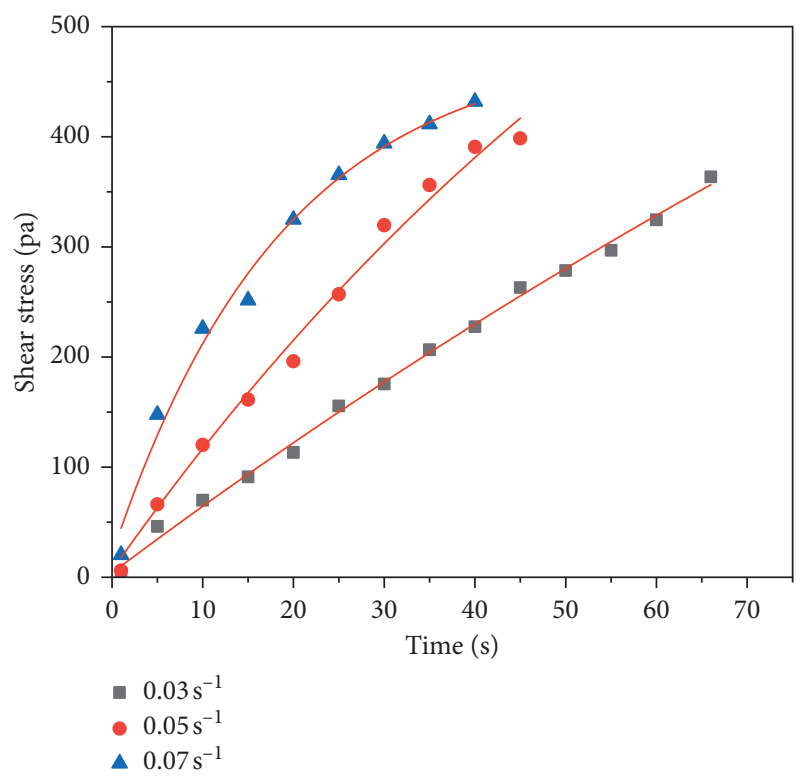

(c)

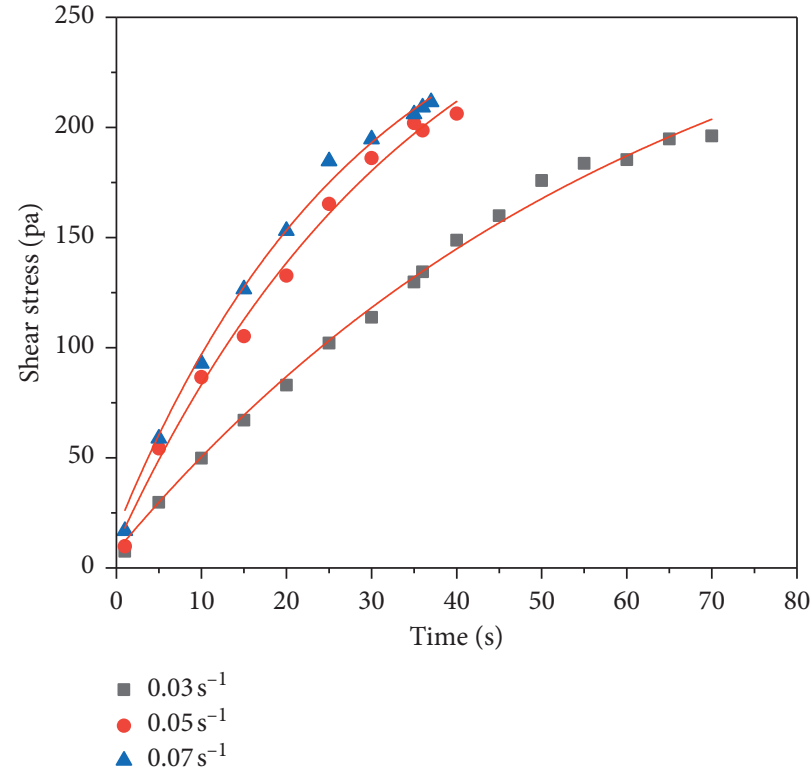

(b)

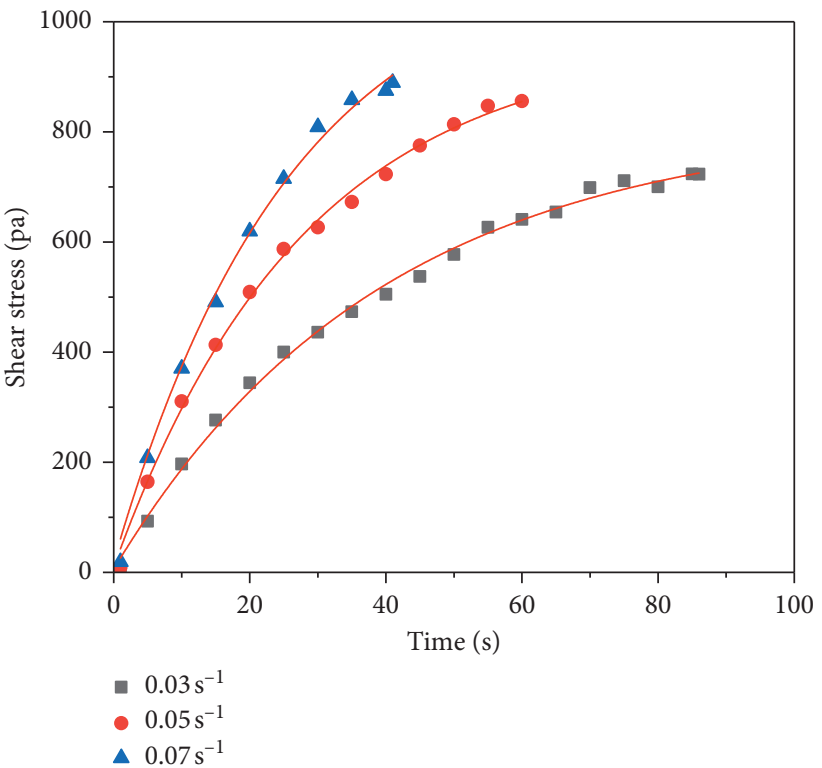

(d)

Figure 7: Stress-time curve of paste slurry in initial structural failure process. Mass concentration (\%): (a) 71; (b) 73; (c) 75; (d) 77.

affected by the viscosity of the object, so that the motion resistance increased, thus causing the measured stress to be excessive; However, from Figures 5(c) and 5(d), when the mass concentration increased, the peak stress of $0.5 \mathrm{~s}^{-1}$ and $1 \mathrm{~s}^{-1}$ was slightly equal to or lower than $0.05 \mathrm{~s}^{-1}$. An excessive shear rate caused the slurry to yield instantaneously. This time process was less than the minimum time interval at which the sensor could acquire the data, making the yielding process unobservable; the resulting data were the stress after yielding [34]. For the data obtained from $0.5 \mathrm{~s}^{-1}$ and $1 \mathrm{~s}^{-1}$, the peak stress of each slurry mass concentration at $1 \mathrm{~s}^{-1}$ was less than $0.5 \mathrm{~s}^{-1}$. It could be seen that when the shear rate exceeded a certain value, the higher the shear rate, the lower the peak value of the shear stress.
Therefore, in the actual operation, the shear rate of the rotor should be reduced as much as possible in order to obtain a relatively stable and smooth stress curve. So, the next test was performed at a shear rate of $0.03 \mathrm{~s}^{-1}$ and $0.07 \mathrm{~s}^{-1}$ around $0.05 \mathrm{~s}^{-1}$ to investigate the effect of low constant shear rate on the initial structural failure process of the paste slurry. The shear stress-time curve was obtained as shown in Figure 6.

\section{Model Verification and Discussion}

The stress-time curves of different mass concentrations paste slurry at low constant shear rates of $0.03 \mathrm{~s}^{-1}, 0.05 \mathrm{~s}^{-1}$, and $0.07 \mathrm{~s}^{-1}$ in the initial structural failure process are shown in 
TABLE 2: Regression results of parameters in the model.

\begin{tabular}{|c|c|c|c|c|c|c|}
\hline $\begin{array}{l}\text { Mass concentration } \\
(\%)\end{array}$ & $\begin{array}{l}\text { Shear rate } \\
\dot{\gamma}\left(\mathrm{s}^{-1}\right)\end{array}$ & $\begin{array}{c}\text { Initial stress } \\
\tau_{0}(\mathrm{pa})\end{array}$ & Yield stress $\tau_{y}(\mathrm{pa})$ & Elastic modulus $G$ (pa) & Yield time $t(\mathrm{~s})$ & Correlation coefficient $R$ \\
\hline \multirow{3}{*}{71} & 0.03 & 7.78 & 98.56 & 153.0 & 59 & 0.9871 \\
\hline & 0.05 & 8.89 & 101.42 & 122.0 & 42 & 0.9938 \\
\hline & 0.07 & 14.96 & 105.80 & 139.1 & 33 & 0.9779 \\
\hline \multirow{3}{*}{73} & 0.03 & 7.52 & 196.19 & 158.3 & 70 & 0.9950 \\
\hline & 0.05 & 9.87 & 206.28 & 173.7 & 40 & 0.9918 \\
\hline & 0.07 & 16.84 & 211.60 & 144.0 & 37 & 0.9944 \\
\hline \multirow{3}{*}{75} & 0.03 & 4.03 & 363.53 & 206.5 & 66 & 0.9965 \\
\hline & 0.05 & 6.11 & 399.56 & 235.8 & 47 & 0.9906 \\
\hline & 0.07 & 20.36 & 431.99 & 368.9 & 40 & 0.9868 \\
\hline \multirow{3}{*}{77} & 0.03 & 5.61 & 723.13 & 691.5 & 86 & 0.9964 \\
\hline & 0.05 & 9.14 & 855.95 & 692.4 & 60 & 0.9967 \\
\hline & 0.07 & 18.99 & 889.29 & 621.2 & 41 & 0.9951 \\
\hline
\end{tabular}

Figure 7. A point was taken every five seconds, wherein the dot plot represented the measured data and the curve represented the predictive effect of equation (8) on the stress-time relationship of the paste in the initial structural failure process. The regression results of the parameters in model are shown in Table 2 . The initial stress $\tau_{0}$, yield stress $\tau_{y}$, and yield time $t$ in the table were measured values.

From Figure 7, it is clear that model equation (8) had a better description and prediction effect on the stress-time relationship of the initial structural failure process for the four mass concentrations paste slurry, and the prediction accuracy was higher and had a strong representativeness. At the same time, in the range of low constant shear rate $(0.03$, 0.05 , and $\left.0.07 \mathrm{~s}^{-1}\right)$, the initial stress and the yield stress increased correspondingly with the increased of shear rate at the same mass concentration and the curve of the initial stage was closer to the $y$-axis, which was reflected by the time to yield was gradually reduce; because the internal structure of the paste slurry was more severely disturbed when the shear rate was increased, it was easier to break the entire structure of the slurry to cause flow and yield. As the mass concentration increased, from Figure 8, it is seen that the yield stress increased exponentially. At low shear rate, there was still an exponential relationship between yield stress and mass concentration, and as the shear rate increased and the magnitude of the yield stress increased [35].

\section{Conclusion}

(1) At constant shear rate, the process of deformation of the paste slurry is divided into two stages: one is the initial structural failure process with increasing shear stress; the other is the thixotropic process with decreasing shear stress after yielding.

(2) According to the Maxwell model, the stress-time relationship model equation describing the initial structural failure stage of the paste under constant shear rate is derived, and the obtained model equation has higher prediction accuracy and better popularity.

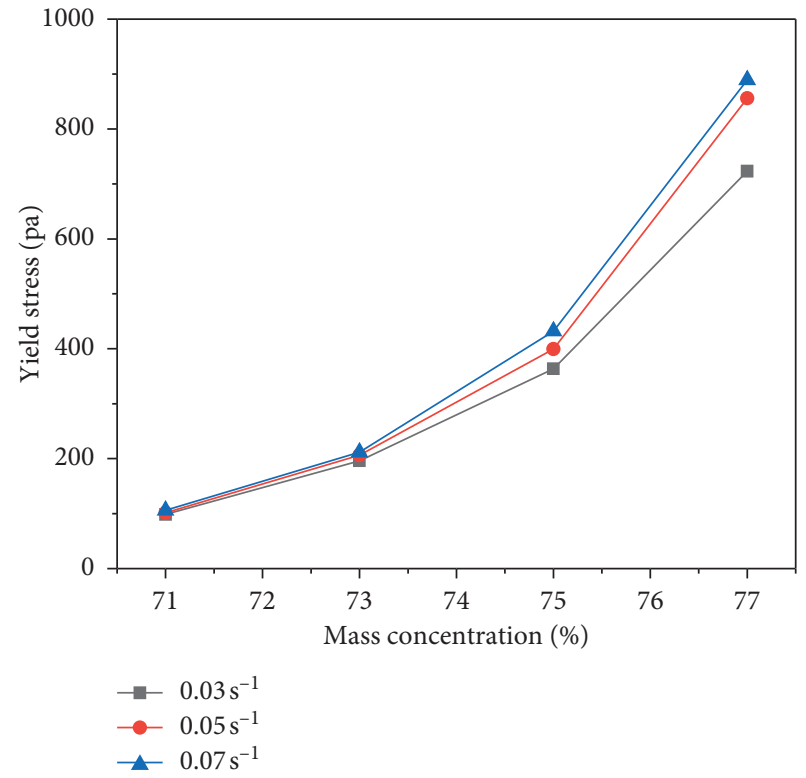

FIGURE 8: Yield stress of slurry at different mass concentrations.

(3) In the initial structural failure stage, the paste has a nonlinear stress-time relationship. At different shear rates $\left(0.05,0.5\right.$, and $\left.1 \mathrm{~s}^{-1}\right)$, the lower the rotation speed, the smoother the curve, and the slurry at various stages in the yielding process can be more clearly reflected; in the range of low constant shear rate $\left(0.03,0.05\right.$, and $\left.0.07 \mathrm{~s}^{-1}\right)$, the initial stress and yield stress of the paste increase with the increases of shear rate at the same mass concentration, and the time to yield is shorter. At low constant shear rates, there is still an exponential relationship between yield stress and mass concentration.

\section{Data Availability}

The data used to support the findings of this study are available from the corresponding author upon request. 


\section{Conflicts of Interest}

The authors declare that there are no conflicts of interest regarding the publication of this paper.

\section{Acknowledgments}

Special thanks go to those researchers who have made great contributions to the project. This work was supported by the State Key Laboratory of High-Efficient Mining and Safety of Metal Mines, Ministry of Education. This research was funded by the National Natural Science Foundation of China (grant number 51574013).

\section{References}

[1] T. Y. Liu, Technology and Application of Filling Mining, Metallurgical Industry Press, Beijing, China, 2001.

[2] D. Q. Deng, Y. T. Gao, and Y. L. Yang, "Rheological properties of full tailings slurry in pipeline transportation based on the hydromechanics theory," Journal of University of Science and Technology Beijing, vol. 31, no. 11, pp. 1380-1384, 2009.

[3] H. Y. Cheng, Characteristics of Rheological Parameters and Pipe Resistance under the Time-Temperature Effect, University of Science and Technology, Beijing, China, 2018.

[4] L. Pullum, A. B. Fourie, and R. J. Jewell, "Pipelining tailings, pastes and backfill," in Proceedings of the Tenth International Seminar on Paste and Thickened Tailings, Perth, Australia, March 2007.

[5] Z. L. Yao, "Theory of and practice in cemented filling with unclassified tailings structure fluid," Mining Research and Development, vol. S1, pp. 15-18+48, 2006.

[6] H. H. Sun, Y. C. Huang, and B. G. Yang, Contemporary Cement Filling Technology, Metallurgical Industry Press, Beijing, China, 2002.

[7] Z. H. Fang, W. N. Ying, and J. T. Tang, "Calculation of hydraulic gradient of solid-liquid two-phase flow," Nonferrous Metals (Mining Section), vol. 5, pp. 5-8+22, 1982.

[8] A. X. Wu and H. J. Wang, Metal Mine Paste Filling Theory and Technology, Science Press, Beijing, China, 2015.

[9] T. Belem and M. Benzaazoua, "Design and application of underground mine paste backfill technology," Geotechnical and Geological Engineering, vol. 26, no. 2, pp. 147-174, 2008.

[10] A. Haimoni and D. J. Hannant, Prediction of Pressure Drop in Pipes for Slurries in Plug Flow, vol. 5, pp. 12-18, Society of Petroleum Engineers, Dallas, TX, USA, 1989.

[11] N. J. Alderman, G. H. Meeten, and J. D. Sherwood, "Vane rheometry of bentonite gels," Journal of Non-Newtonian Fluid Mechanics, vol. 39, no. 3, pp. 291-310, 1991.

[12] J. J. Assaad, J. Harb, and Y. Maalouf, "Effect of vane configuration on yield stress measurements of cement pastes," Journal of Non-Newtonian Fluid Mechanics, vol. 230, pp. 3142, 2016.

[13] N. Q. Nguyen and D. V. Boger, "Direct yield stress measurement with the vane method," Journal of Rheology, vol. 29, no. 3, p. 335, 1985.

[14] P. Bassoullet and P. Le Hir, "In situ measurements of surficial mud strength: a new vane tester suitable for soft intertidal muds," Continental Shelf Research, vol. 27, no. 8, pp. 12001205, 2007.

[15] D. Fraggedakis, Y. Dimakopoulos, and J. Tsamopoulos, "Yielding the yield-stress analysis: a study focused on the effects of elasticity on the settling of a single spherical particle in simple yield-stress fluids," Soft Matter, vol. 12, no. 24, pp. 5378-5401, 2016.

[16] H. Hu, H. H. Sun, and B. G. Yang, "Rheological model and equation of viscoelastic-plasticity of paste-like backfill pulp," Journal of China University of Mining and Technology, vol. 32, no. 2, pp. 16-19, 2003.

[17] J. J. Assaad, J. Harb, and Y. Maalouf, "Measurement of yield stress of cement pastes using the direct shear test," Journal of Non-newtonian Fluid Mechanics, vol. 214, pp. 18-27, 2014.

[18] A. X. Wu, H. Z. Jiao, and H. J. Wang, "Mechanical model of scraper rake torque in deep-cone thickener," Journal of Central South University (Science and Technology), vol. 43, no. 4, pp. 1469-1474, 2012.

[19] D. Tanjore, A New Application for Brookfield Viscometers: Viscoelastic Property Determination, North Carolina State University, Raleigh, NC, USA, 2005.

[20] M. Dinkgreve, M. M. Denn, and D. Bonn, "“Everything flows?": elastic effects on startup flows of yield-stress fluids," Rheologica Acta, vol. 56, no. 3, pp. 189-194, 2017.

[21] A. W. Saak, H. M. Jennings, and S. P. Shah, "The influence of wall slip on yield stress and viscoelastic measurements of cement paste," Cement and Concrete Research, vol. 31, no. 2, pp. 205-212, 2001.

[22] J. Yan and A. E. James, "The yield surface of viscoelastic and plastic fluids in a vane viscometer," Journal of Non-Newtonian Fluid Mechanics, vol. 70, no. 3, pp. 237-253, 1997.

[23] V. C. Kelessidis and R. Maglione, "Yield stress of waterbentonite dispersions," Colloids and Surfaces A: Physicochemical and Engineering Aspects, vol. 318, no. 1-3, pp. 217-226, 2008.

[24] R. R. Fernandes, D. E. V. Andrade, A. T. Franco, and C. O. R. Negrão, "The yielding and the linear-to-nonlinear viscoelastic transition of an elastoviscoplastic material," Journal of Rheology, vol. 61, no. 5, pp. 893-903, 2017.

[25] A. X. Wu, H. Z. Jiao, and H. J. Wang, "Yield stress measurements and optimization of paste tailings," Journal of Central South University (Science and Technology), vol. 44, pp. 3370-3376, 2013.

[26] J. D. Sherwood, "Transient flow of viscoelastic, thixotropic fluid in a vane rheometer or infinite slot," Journal of NonNewtonian Fluid Mechanics, vol. 154, no. 2-3, pp. 109-119, 2008.

[27] A. Malkin, V. Kulichikhin, and S. Ilyin, "A modern look on yield stress fluids," Rheologica Acta, vol. 56, no. 3, pp. 177-188, 2017.

[28] V. L. Petra and V. B. David, "Yield stress measurements with the vane," Journal of Non-Newtonian Fluid Mechanics, vol. 63, pp. 235-261, 1996.

[29] W. S. Aaron, M. J. Hamlin, and P. S. Surendra, "The influence of wall slip on yield stress and viscoelastic measurements of cement paste," Cement and Concrete Research, vol. 31, pp. 205-212, 2001.

[30] J. Xiao, D. F. Wang, and S. H. Zuo, "Influence of temperature on structure of fresh cement paste with low shear rate," Journal of Building Materials, vol. 20, no. 6, pp. 835-839, 2017.

[31] G. Q. Zhou and X. M. Liu, Viscoelastic Theory, China University of Science and Technology Press, Hefei, China, 1996.

[32] D. Q. Deng, L. Liu, Z. L. Yao, K. I.-I. L. Song, and D. Z. Lao, "A practice of ultra-fine tailings disposal as filling material in a gold mine," Journal of Environmental Management, vol. 196, pp. 100-109, 2017.

[33] N. J. Alderman, G. H. Meeten, and J. D. Sherwood, "Vane rheometry of bentonite gels," Journal of Non-Newtonian Fluid Mechanics, vol. 39, no. 3, pp. 291-310, 1991. 
[34] F. Y. Lyu, Y. Y. Qu, N. X. Zhang, J. Gao, X. D. Hao, and $\mathrm{M}$. Wu, "Yield stress measurement of dense pastes with pipe transport and vane," Journal of Dispersion Science and Technology, vol. 37, no. 11, pp. 1563-1569, 2016.

[35] S. Y. Wang, A. X. Wu, and S. H. Yin, "Influence factors of pressure loss in pipeline transportation of paste slurry," Chinese Journal of Engineering, vol. 37, no. 1, pp. 7-12, 2015. 


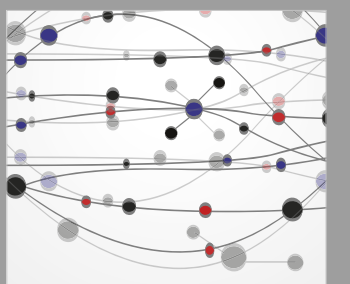

The Scientific World Journal
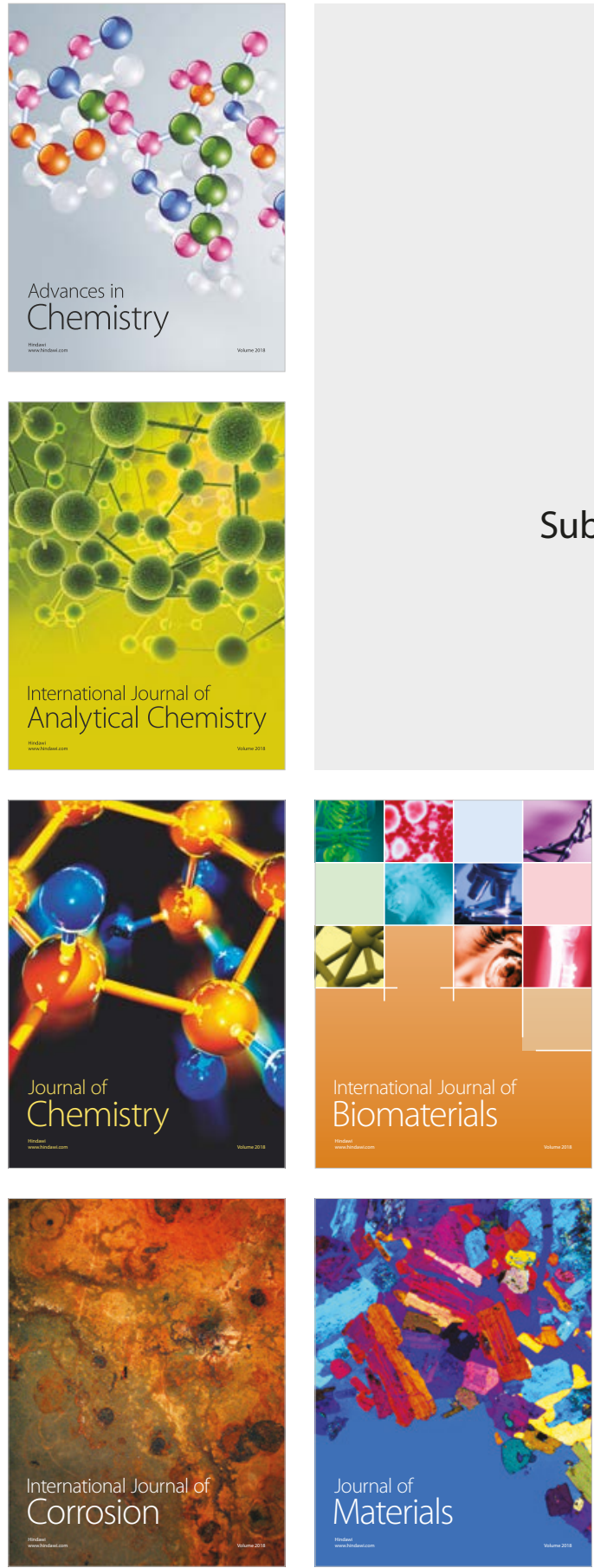

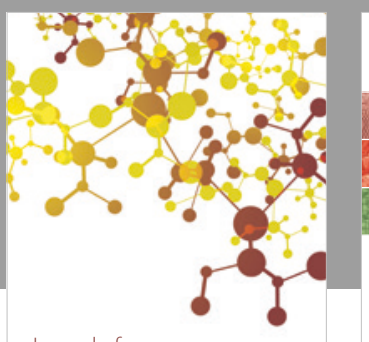

Journal of

Applied Chemistry
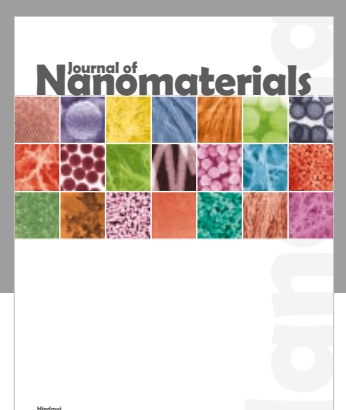

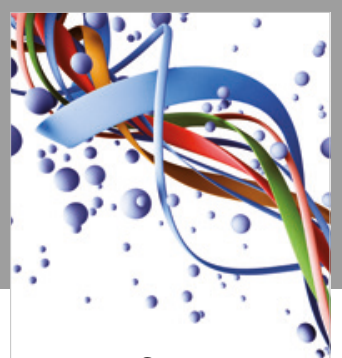

Scientifica

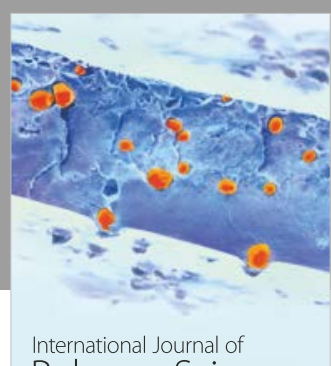

Polymer Science

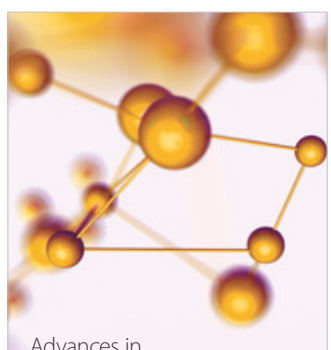

Physical Chemistry
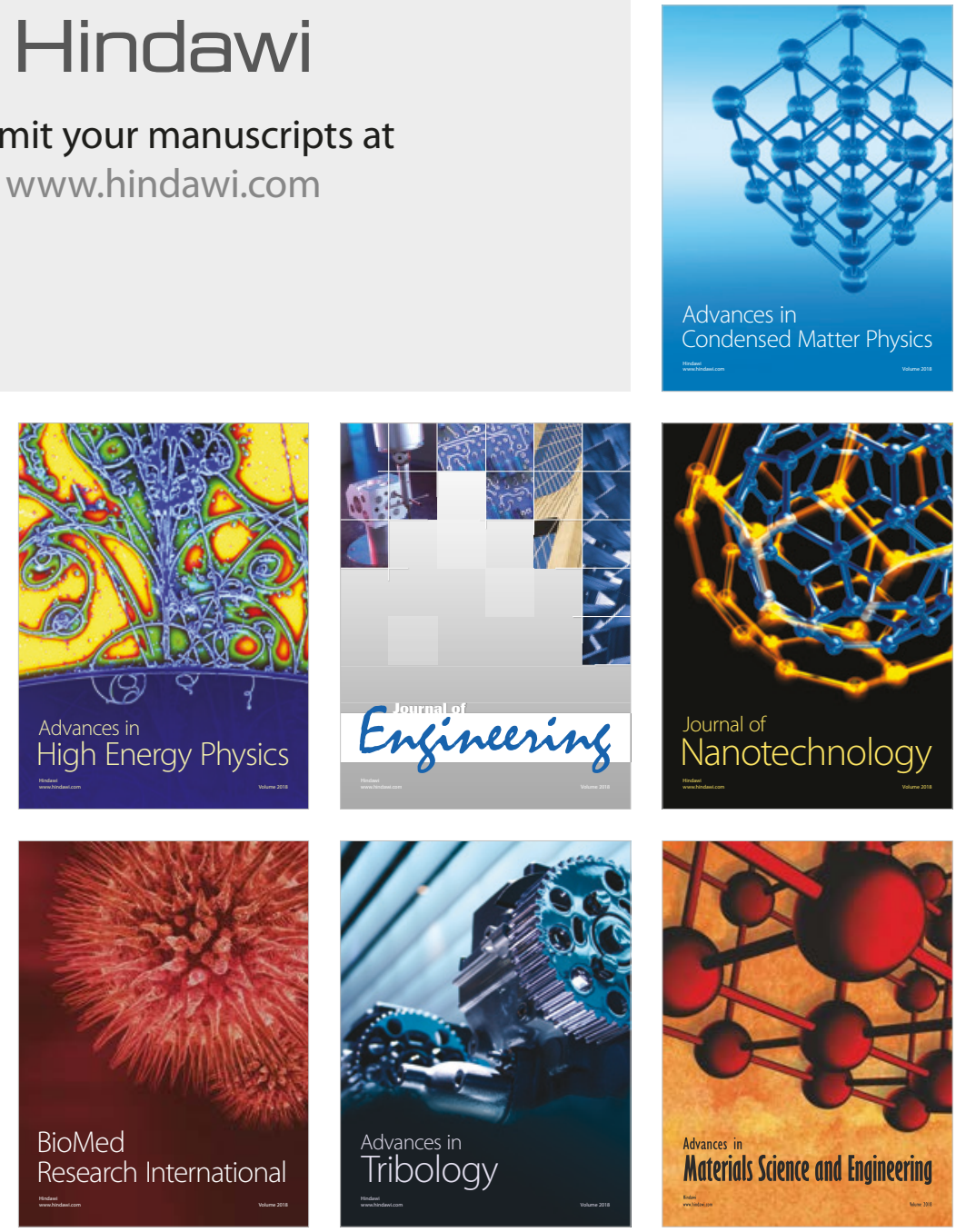